compared to Ig genes. Thus, although more accurate estimates must await further information, it is possible that pol $\eta$ may be responsible for one-third of somatic mutations. This is, of course, a hypothesis based on a correlation of Ig gene mutational specificity and pol $\eta$ error specificity. It needs to be challenged as per Dörner and Lipsky, and

\section{Response 2}

\section{Patricia J. Gearhart and Xianmin Zeng \\ Laboratory of M olecular Gerontology, N ational Institute on Aging, National Institutes of Health, Baltimore, MD 21224, USA. (gearhartp@ grc.nia.nih.gov)}

Rogozin et al. ${ }^{1}$ report that the WA motif is frequently mutated in $\mathrm{V}$ genes and that because pol $\eta$ preferentially miscopies $A$ and $T$ in vitro, especially when the two nucleotides are in WA, it may play a role in hypermutation. In contrast, Dörner and Lipsky argue that pol $\eta$ can only play a minor role because mutations occur more frequently in RGYW/WRCY than in WA Two issues are being discussed here: first, is pol $\eta$ involved in hypermutation of $A$ and $\mathrm{T}$ and second, is the WA motif important? We have directly addressed these questions by it requires further testing to disprove. The hypothesis does not diminish the importance of an R $\underline{G Y W}$ mutator and it clearly implies roles for other DNA polymerases and more than one mechanism for introducing base substitutions during SHM of Ig genes.

1. Rogozin, I. B., Pavlov,Y. I., Bebenek, K., Matsuda,T. \& Kunkel,T.
A. Nature Immunol, 2 530-536 (2001).

2. Rogozin, I. B. \& Kolchanov, N . A. Biochim. Biophys. Acta 1171 11-18 (1992).

3. Milstein, C., N euberger, M. S. \& Staden, R. Proc. N atl Acad. Sci. USA 95, 8791-8794 (1998)

4. Zeng, X. et al. Nature. Immunol 2, 537-541 (2001).

5. Goodman, M. F. \& Tippin, B. Nature Rev. Cell Mol. Biol. 1 101-109 (2000).

6. Frank, E. G. et al. EM BO J. 20, 2914-2922 (2001)

7. Diaz, M.,Verkoczy, L. K., Flajnik, M. F. \& Klinman, N. R. K. J. Immunol. 167, 327-35 (2001)

8. Matsuda, T. et al. J. Mol. Biol. 14,335-346 (2001) examining mutations in $\mathrm{V}$ gene from three individuals with the variant form of the disease XP$\mathrm{V}$; these individuals did not express pol $\eta$, due to independent genetic defects ${ }^{2}$. If pol $\eta$ is involved, the frequency of mutations of $\mathrm{A}$ and $\mathrm{T}$ should decrease in XP-V clones. This is indeed the case: only $15 \%$ of the total mutations occurred at $\mathrm{A}$ and $\mathrm{T}$ bases in XP-V clones (41 of 272) versus $45 \%$ in control clones (128 of 286). This marked shift in the mutational spectrum in XP$\mathrm{V}$ clones implies that pol $\eta$ participates in the hypermutation process.

Whether mutations occur in the WA motif is a separate issue. As Dörner and Lipsky point out, WA can be located within the RGYW/WRCY motifs and outside them. In our study, $17 \%$ of total mutations were in WA located in RGYW/WRCY in control clones versus $2 \%$ in $\mathrm{XP}-\mathrm{V}$ clones; $11 \%$ of total mutations occurred in WA outside RGYW/WRCY in control clones versus $6 \%$ in XP-V clones; and $17 \%$ of total mutations were of $\mathrm{A}$ and $\mathrm{T}$ in non-WA motifs in control clones versus $7 \%$ in XP-V clones. This shows that in the absence of pol $\eta$, there was a lower frequency of $\mathrm{A}$ and $\mathrm{T}$ mutations, whether they were in WA sequences or not. The data support a model in which pol $\eta$ preferentially miscopies $\mathrm{A}$ and $\mathrm{T}$ wherever they are found. This would happen in $\mathrm{V}$ genes because the pol has access to the template at the frequent strand breaks.

1. Rogozin, I. B., Pavlov, Y. I., Bebenek, K., Matsuda, T. \& Kunkel, T. A Nature Immunol. 2, 530-536 (2001)

2. Zeng, X.,W inter, D. B., Kasmer, C., Kraemer, K. H., Lehmann, A. R. \& G earhart, P. J. Nature Immunol. 2, 537-541 (2001). 